\title{
Comunicação
}

(Communication)

\section{Precocidade sexual em bovinos Nelore avaliada por ultrassonografia testicular}

\author{
[Sexual precocity in Nelore bovines evaluated by testicular ultrasonography] \\ D.J. Cardilli ${ }^{1}$, G.H. Toniollo ${ }^{2}$, A.A. Pastore ${ }^{3}$, J.C. Canola ${ }^{2}$, \\ J.A. Oliveira ${ }^{2}$, M.E.Z. Mercadante ${ }^{4}$ \\ ${ }^{1}$ Pós-doutorando do Programa de Pós-Graduação em Saúde Animal na Amazônia- UFPA - Castanhal, PA \\ ${ }^{2}$ FCAV-Unesp-Jaboticabal - Jaboticabal, SP \\ ${ }^{3}$ Médico Veterinário CRV-Lagoa \\ ${ }^{4}$ Estação Experimental de Zootecnia - Sertãozinho, SP
}

Ao exame de ultrassom, o parênquima testicular de bovinos é homogêneo e tem ecogenicidade moderada (Pechman e Eilts, 1987; Cardilli et al., 2010), a qual aumenta com a idade do animal (Chandolia et al., 1997; Aravindakshan et al., 2000; Kastelic, 2001; Brito et al., 2004; AbdelRazek e Ali, 2005; Cardilli et al., 2012).

A circunferência escrotal é o melhor indicador de puberdade em bovinos Nelore e pode ser utilizada na seleção de touros para precocidade sexual (Brito et al., 2004). Alguns autores tentaram estabelecer a importância da ultrassonografia testicular como indicador de precocidade sexual ou de potencial reprodutivo dentro de um rebanho, fundamentados em resultados nos quais animais púberes tiveram o parênquima testicular mais ecogênico que os prépúberes na mesma idade (Aravindakshan et al., 2000; Brito et al., 2004).

Brito et al. (2004) informaram que bovinos Nelore criados em sistema extensivo dificilmente apresentam sêmen compatível com puberdade antes dos 16 meses de idade; a mesma observação foi feita por Cardilli et al. (2012). No presente estudo, buscaram-se animais com sêmen compatível com puberdade antes dos 16 meses, com o intuito de verificar se esses animais apresentavam maior ecogenicidade testicular que aqueles não púberes na mesma idade, a fim de demonstrar a importância da ultrassonografia como indicador de precocidade sexual ou potencial reprodutivo dentro de um rebanho. Este estudo se baseou nos resultados obtidos por

Recebido em 6 de abril de 2013

Aceito em 19 de fevereiro de 2014

E-mail: djcardilli@yahoo.com.br
Freneau et al. (2006), os quais relataram que a idade média de puberdade para bovinos Nelore criados em sistema extensivo foi de 15 meses, bem como no fato de que, neste caso, tratava-se de animais criados em sistema intensivo, já que a nutrição é um relevante fator que interfere na idade à puberdade.

Foram realizados exames ultrassonográficos em testículos de 111 bovinos da raça Nelore, os quais faziam parte de um mesmo rebanho, criado em sistema intensivo, na cidade de SertãozinhoSP (latitude $-21^{\circ} 08^{\prime} 16^{\prime \prime}$ e longitude 47 59' 25"). Os animais foram mantidos durante todo o período de realização da pesquisa com uma dieta de $14 \%$ de proteína bruta e $63 \%$ de energia.

Os exames ultrassonográficos foram realizados com aparelho Pie Medical Scanner 200C, ligado a um transdutor linear de $8 \mathrm{MHz}$. Após contensão dos animais em tronco e aplicação de gel acústico diretamente sobre a bolsa testicular, foram realizadas varreduras em planos transversais e longitudinais nos testículos direito e esquerdo. Ao início de cada dia de trabalho, o aparelho de ultrassonografia foi calibrado sempre de uma mesma maneira quanto à intensidade de brilho e também quanto à posição do foco principal.

As imagens selecionadas foram transferidas diretamente ao computador por meio do software Eview-Echo Image Viewer, versão 1.00, Pie Medical Equipament B.V., copyright Pie Medical (EIV). Com o auxílio do software EIV, foram selecionadas duas regiões de interesse (RI) 
em cada plano de varredura nos testículos direito e esquerdo. Cada RI foi delimitada por um quadrado de $6,3 \mathrm{~mm}$ de lado e estava localizada lateral e medialmente ao mediastino testicular no plano transversal e nas faces ventral e dorsal do testículo, excluindo-se o mediastino testicular, no plano longitudinal. As RI contiveram o máximo de parênquima testicular, sem englobar pele, túnicas, epidídimo e o mediastino testicular.

Automaticamente, o software EIV calculou a ecogenicidade do parênquima testicular nas RI, em uma escala que variou de zero a $100 \%$, sendo $0 \%$ para uma imagem totalmente preta ao monitor (parênquima testicular menos ecogênico) e $100 \%$ para uma imagem totalmente branca (parênquima testicular mais ecogênico). Também por meio do software EIV foram feitas as aferições da espessura do mediastino testicular, sempre no plano longitudinal de varredura dos testículos.

Os exames andrológicos foram feitos segundo a metodologia descrita por Krause (1993).

A colheita do sêmen foi realizada por eletroejaculação aos 13 e 15 meses de idade, sempre após os exames ultrassonográficos. Os parâmetros avaliados e a metodologia de análise do sêmen foram as mesmas utilizadas por Brito et al. (2004).
O parâmetro estabelecido para a puberdade neste estudo foi: ejaculado com mínimo de $50 \times 10^{6}$ espermatozoides, pelo menos $10 \%$ de motilidade progressiva e $70 \%$ ou mais de células normais no ejaculado, semelhante ao utilizado por Brito et al. (2004).

A ecogenicidade do parênquima testicular foi analisada pelo método dos quadrados mínimos, por meio do procedimento General Linear Model (GLM) do programa SAS (SAS 9.1, SAS Institute, Cary, NC, USA), utilizando-se um modelo que incluiu os efeitos de touro (1-111), planos (longitudinal e transversal), testículos (direito e esquerdo), idade e interações entre esses efeitos. Quando o efeito ou a interação foi significativa pelo teste $\mathrm{F}$, as médias foram comparadas pelo teste Tukey a $5 \%$ de probabilidade.

Entre os 111 animais, 4 apresentaram sêmen compatível com puberdade aos 15 meses de idade (Tab. 1), e a média da ecogenicidade do parênquima testicular dos nove aos 15 meses foi significativamente maior nos animais púberes quando comparados com os pré-púberes na mesma idade, respectivamente, $35,66 \%$ e $30,44 \%$. A diferença de ecogenicidade entre animais púberes e pré-púberes passou a ser significativa a partir dos 13 meses (Tab. 2).

Tabela 1. Análise do sêmen dos animais púberes aos 15 meses de idade. Unesp - Jaboticabal, SP, 2013

\begin{tabular}{cccccccc}
\hline Touros & $\begin{array}{c}\text { Volume do } \\
\text { ejaculado } \\
(\mathrm{mL})\end{array}$ & $\begin{array}{c}\text { Motilidade } \\
(\%)\end{array}$ & $\begin{array}{c}\text { Vigor } \\
(0-5)\end{array}$ & $\begin{array}{c}\text { Concentração } \\
\left(\mathrm{x} 10^{6} / \mathrm{mm}^{3}\right)\end{array}$ & $\begin{array}{c}\text { Defeitos } \\
\text { maiores } \\
(\%)\end{array}$ & $\begin{array}{c}\text { Defeitos } \\
\text { menores } \\
(\%)\end{array}$ & $\begin{array}{c}\text { Defeitos } \\
\text { totais } \\
(\%)\end{array}$ \\
\hline 2 & 5 & 50 & 3 & 1000 & 4 & 6 & 10 \\
7 & 4 & 10 & 2 & 100 & 6 & 5 & 11 \\
10 & 4 & 10 & 2 & 300 & 4 & 3 & 7 \\
11 & 4 & 25 & 2 & 300 & 5 & 3 & 8 \\
\hline
\end{tabular}

Tabela 2. Média da ecogenicidade do parênquima testicular para os animais púberes e pré-púberes em cada momento de avaliação. Unesp - Jaboticabal, SP, 2013

\begin{tabular}{ccc}
\hline Meses & $\begin{array}{c}\text { Púberes } \\
(\%)\end{array}$ & $\begin{array}{c}\text { Pré-púberes } \\
(\%)\end{array}$ \\
\hline 9 & $19,25 \mathrm{a}$ & $19,02^{\mathrm{a}}$ \\
13 & $43,16 \mathrm{a}$ & $33,15 \mathrm{~b}$ \\
15 & $44,57 \mathrm{a}$ & $39,15 \mathrm{~b}$ \\
\hline
\end{tabular}

Médias seguidas de letras diferentes entre as linhas diferem estatisticamente pelo teste Tukey $(\mathrm{P}<0,05)$.
Aravindakshan et al. (2000) e Brito et al. (2004), ao trabalharem com as raças Hereford e Canchim, respectivamente também encontraram resultados semelhantes ao do presente estudo e sugeriram que a ultrassonagrafia pode ser utilizada como um indicador de precocidade sexual. Brito et al. (2004) concluíram que a circunferência escrotal foi melhor indicador de precocidade sexual do que a medida da ecogenicidade do parênquima testicular, pois apresentou maiores valores em testes de sensibilidade e especificidade para essa característica. 
Cardilli et al. (2012), em um estudo com bovinos Nelore criados em sistema extensivo, relataram resultados contraditórios àqueles apresentados acima, Esses autores não encontraram diferença significativa na ecogenicidade do parênquima testicular entre animais púberes e pré-púberes na mesma idade. Vale ressaltar, entretanto, que o presente estudo foi feito com um maior número de animais, criados em sistema intensivo, haja vista a grande importância da nutrição na reprodução.
Com base nos resultados encontrados no presente estudo, sugere-se que a ultrassonografia testicular pode ser utilizada como indicador de precocidade sexual, já que animais púberes apresentam maior ecogenicidade testicular que os pré-púberes na mesma idade.

Palavras-chave: touro, trato reprodutor masculino, ecografia

\begin{abstract}
The present study aimed to evaluate if there are differences in testicular parenchyma echogenicity between pre-pubescent and pubescent animals at the same age. Ultrasound examinations were performed in longitudinal and transversal planes of the testicles of 111 healthy Nelore bovines, at the ages of nine, 13 and 15 months. The EIV software calculated the echogenicity of the testicular parenchyma, which ranged from 0 (anechoic) to 100\% (hyperechoic). Animals that had reached puberty at 15 months of age presented higher testicular echogenicity than the animals that had not reached puberty at the same age. These results suggest that testicular ultrasonography can be used as a predictor of sexual precocity.
\end{abstract}

Keywords: bull, male reproductive tract, ecography

\section{REFERÊNCIAS}

ABDEL-RAZEK, A.K.; ALI, A. Development changes of bull (Bos taurus) genitalia as evaluated by caliper and ultrasonography. Reprod. Dom. Anim., v.40, p.23-27, 2005.

ARAVINDAKSHAN, J.P.; HONARAMOOZ, A.; BARTLEWSKI, P.M. et al. Pattern of gonadotropin secretion and ultrasonographic evaluation of developmental changes in the testis of early and late maturing bull calves. Theriogenology, v.54, p.339-354, 2000.

BRITO, L.F.C.; SILVA, A.E.D.F.; UNANIAM, M.M. et al. Sexual development in early and late maturing Bos indicus and Bos indicus $x$ Bos Taurus crossbred bulls in Brazil. Theriogenology, v.62, p.1198-1217, 2004.

CARDILLI, D.J.; TONIOLLO, G.H.; PASTORE, A.A. et al. Ultrassonografia testicular em bovinos jovens da raça Nelore criados em sistema extensivo. Arq. Bras. Med. Vet. Zootec., v.64, p.75-82, 2012.

CARDILLI, D.J.; TONIOLLO, G.H.; PASTORE, A.A. et al. Padrão ultrassonográfico do parênquima, mediastino e túnicas testiculares em bovinos jovens da raça nelore. Cienc. Anim. Bras., v.11, p.899 - 905, 2010.
CHANDOLIA, R.K.; HONARAMOOZ, A.; OMEKE, B.C. et al. Assessment of development of the testes and accessory glands by ultrasonography in bull calves and associated endocrine changes. Theriogenology, v.48, p.119132, 1997.

FRENEAU, G.E.; VALE FILHO, V.R.; MARQUES JR, A.P. et al. Puberdade em touros Nelore criados em pasto no Brasil: características corporais, testiculares e seminais e de índice de capacidade andrológica por pontos. Arq. Bras. Med. Vet. Zootec., v.58, p.1107-1115, 2006.

KASTELIC, J.P.; COOK, R.B.; PIERSON, R.A. et al. Relationships among scrotal and testicular characteristics, sperm production, and seminal quality in 129 beef bulls. Can. J. Vet. Res., v.65, p.111-115, 2001.

KRAUSE, D. Sistema Reprodutor Masculino. In: DIRKSEN, G.; GRUNDER, U.; STORBER, M. Exame Clínico dos Bovinos. Rio de Janeiro: Guanabara Koogan, 1993. p.242-268.

PECHMAN, R.D.; EILTS, B.E. B-mode ultrasonography of the bull testicle. Theriogenology, v.27, p.431-441, 1987. 